\title{
Article \\ Mental Health Status of People with Multiple Sclerosis during the COVID-19 Pandemic
}

\author{
Maciej Wilski ${ }^{1, *(\mathbb{D}}$, Magdalena Koper ${ }^{1}\left(\mathbb{D}\right.$, Jarosław Gabryelski ${ }^{2}$, Waldemar Brola ${ }^{3}\left(\mathbb{D}\right.$ and Tomasz Tasiemski $^{1}{ }^{1}$ \\ 1 Department of Adapted Physical Activity, Poznań University of Physical Education, 61-871 Poznan, Poland; \\ koper@awf.poznan.pl (M.K.); tasiemski@awf.poznan.pl (T.T.) \\ 2 Division of Rehabilitation Engineering, Institute of Combustion Engines and Transport, Faculty of Machines \\ and Transport, Poznan University of Technology, 60-965 Poznan, Poland; jaroslaw.gabryelski@put.poznan.pl \\ 3 Department of Neurology, Specialist Hospital in Końskie, Collegium Medicum, Jan Kochanowski University, \\ 25-369 Kielce, Poland; wbrola@wp.pl \\ * Correspondence: wilski@awf.poznan.pl; Tel.: +48-8355163; Fax: +48-8330039
}

Citation: Wilski, M.; Koper, M.; Gabryelski, J.; Brola, W.; Tasiemski, T. Mental Health Status of People with Multiple Sclerosis during the COVID-19 Pandemic. J. Clin. Med. 2022, 11, 576. https://doi.org/ $10.3390 / \mathrm{jcm} 11030576$

Academic Editors: Simona Bonavita and Elisabetta Signoriello

Received: 17 December 2021

Accepted: 21 January 2022

Published: 24 January 2022

Publisher's Note: MDPI stays neutral with regard to jurisdictional claims in published maps and institutional affiliations.

Copyright: (C) 2022 by the authors. Licensee MDPI, Basel, Switzerland. This article is an open access article distributed under the terms and conditions of the Creative Commons Attribution (CC BY) license (https:// creativecommons.org/licenses/by/ $4.0 /)$.

\begin{abstract}
Objective. This study assesses and compares the mental health status of people with multiple sclerosis (PwMS) in Poland during the second wave of the Coronavirus Disease 2019 (COVID-19) pandemic (November 2020) to a similar group whose mental health status was examined in November 2017. It also analyzed the psychological resources such as self-efficacy and health locus of control (HLC) and their relationship to mental health in both groups. Methods. Cross-sectional study included two groups of PwMS with 113 respondents each. The respondents completed the General Health Questionnaire-12 and questionnaires for assessing self-efficacy and HLC. The clinical and demographic data of participants were also collected. Results. No differences in mental health status were observed between the studied groups. A hierarchical regression model of the group studied in 2020 revealed that general self-efficacy $(\beta=-0.21, p=0.032)$, HLC -internal $(\beta=-0.21$, $p=0.035)$, and education ( $\beta=-0.18, p=0.048$ ) explained $18 \%$ of the variance in the mental health of PwMS, whereas according to the model of the group assessed in 2017 self-efficacy $(\beta=-0.31$, $p<0.001)$, HLC — chance $(\beta=0.45, p<0.001)$, and HLC-internal $(\beta=-0.37, p<0.001)$ explained $48 \%$ of the variance. Conclusions. Study results suggest that the pandemic and the related lockdown had no effect on the mental health status of PwMS. At the same time, it was noted that well known determinants of mental health such as self-efficacy and HLC seemed to retain their prominent role for mental functioning in the pandemic.
\end{abstract}

Keywords: mental health; multiple sclerosis; COVID-19; self-efficacy; health locus of control

\section{Introduction}

The Coronavirus Disease 2019 (COVID-19) pandemic infection first occurred in China in December 2019 and quickly spread throughout the world. It was eventually declared as a global pandemic on March 11, 2020. As of November 2021, more than 267 million confirmed COVID-19 cases have been identified and over 5 million deaths were reported worldwide. In Poland, severe acute respiratory syndrome coronavirus 2 (SARS-CoV-2) infection was first officially reported at the beginning of March 2020. Before 19 September 2020, the number of daily new cases did not exceed 1000. However, the second wave of the pandemic hit the country a few weeks later and with much greater power (with more than 30,000 new cases a day, toward the end of November) [1]. According to the Eurostat data, Poland had the highest rate of excess deaths compared to other European Union member states in 2020. In November 2020, the excess death rate in Poland reached 97\%, with nearly twice as many deaths as usual in the month. Considering the epidemiological situation of the country, the government imposed a restrictive lockdown on October 24.

At that stage of the pandemic, the effect of COVID-19 on immune diseases such as multiple sclerosis (MS) was unknown. It was believed that people with MS (PwMS) may be 
at an increased risk of SARS-CoV-2 infection and complications due to their immunocompromised state, MS-related comorbidities, and use of immunosuppressive therapies [2,3]. Their feeling of insecurity was exacerbated by questions about the course of COVID-19 in PwMS, the effect of COVID-19 on the course of MS, restrictions in access to health care, misinformation, lack of vaccines, and concern about vaccination in PwMS. Moreover, PwMS had to experience the social effects of lockdown such as limited social interactions, quarantine, changes in daily routine, loss of income, fear of losing a job, uncertainty about the future, loss of loved ones, and fear of contracting COVID-19. All these factors have been shown by early studies to have had a negative impact on mental health or exacerbate preexisting psychiatric challenges, in both the general population and people with chronic disorders [4-7]. In addition, regardless of the pandemic, the prevalence of depression and anxiety is greater among PwMS compared to the general population [8], and so PwMS have a higher risk of developing mental health disorders.

Studies assessing the relationship between the pandemic and the mental state of PwMS have reported varied results. While some have associated the COVID-19 pandemic with a higher level of negative mental health indicators (such as depression or anxiety) [3,9-13], the results of some studies do not confirm this relationship [2,14-17]. This discrepancy in results may be due to the use of different methodologies in studies: some studies were qualitative and were based on an interview, and some did not include a control group or included healthy individuals as controls. Furthermore, most of the studies available in the literature were conducted in the Italian population. Another reason for the inconsistent results may be a limited analysis of the other possible factors that may significantly influence the functioning of an individual during a pandemic. For example, lockdown and the resulting social environment may affect an individual's perception of potential opportunities to act in the context of his/her own health. The imposed restrictions and the prevailing sense of uncertainty may contribute to reducing the psychological resources essential for good mental functioning, such as the sense of self-efficacy or health locus of control (HLC). Previous research results have clearly indicated that these personal resources enable PwMS to effectively cope with the disease or difficulties of daily life and manage the treatment process on their own, which directly translates into their mental functioning [18-21].

Self-efficacy refers to an individual's belief that he/she can accomplish a specific situation or a task and reflects an individual's confidence in coping with a difficult, demanding, or limiting situation [22]. During the COVID-19 pandemic, several studies reported that higher general self-efficacy was related to less mental health problems in several populations $[23,24]$. There are no data available for PwMS.

The HLC has three categories: internal HLC refers to individuals' belief that their own behaviors affect their health status, whereas external HLC refers to individuals' belief that their health is attributed to other people-mainly medical professionals-or chance variables such as luck and fate. The latest research shows that HLC plays an important role in moderating the association of COVID-19 stress and mental distress in general population [25]. Researchers indicate that the locus of control shifted significantly from internal to external during the pandemic in the studied groups, which is explained by increased feelings of powerlessness in the early phase of the pandemic [26,27]. So far, no research in this area has been performed in the PwMS.

Taking the above into account, there is a need to assess the mental health status of PwMS during the pandemic. Our study also included a group of PwMS, with comparable demographic and clinical variables, as a control group, whose mental health status and psychological resources were examined 3 years earlier in the same period of the year (November 2017). Within this context, we aimed to (1) compare mental health status of PwMS studied in 2020 and control group studied in 2017; (2) compare the level of psychological resources such as self-efficacy and HLC in study and control group; (3) evaluate the extent to which socio-demographic, clinical, and psychological factors are associated with mental health in both groups. 


\section{Materials and Methods}

\subsection{Participants and Procedures}

This cross-sectional study included two groups of PwMS who were enrolled in November 2017 and 2020 with the help of the Department of Neurology at Specialist Hospital in Konskie, Poland. Each group consisted of 113 PwMS recruited using the same criteria and principles. The inclusion criteria for the study were as follows: (1) diagnosis of definite MS by a neurologist according to the revised McDonald criteria [28]; (2) no relapse in the last 30 days before the enrollment; (3) absence of cognitive problems and/or psychiatric disorders as confirmed by a neurologist; (4) absence of any concomitant disease. An additional criterion set for the recruitment of the 2020 group was the current lack of symptoms and a diagnosis of COVID-19. The participants were recruited by a research team member during their control visit at the clinic. After providing verbal instructions and explaining the purpose of the study, the individuals were asked if they were interested to participate. Those who were willing to take part in the study were asked to read and complete a questionnaire in a quiet room allocated specifically for this purpose. The study adhered to the ethical standards of the Declaration of Helsinki, and written informed consent was obtained from all the participants prior to the study. After receiving the set of forms, the questionnaire was immediately checked for completeness, and the respondents were asked to fill all potential gaps. The STROBE checklist for cross-sectional studies was used for reporting the study. Ethical approval was obtained from the Bioethical Commission of Poznan University of Medical Sciences.

\subsection{Measures}

All research tools used in the study were standardized and validated in many previous studies on various groups of patients, including PwMS. The mental health of the participants, which was the dependent variable of this study, was evaluated using the Polish version of General Health Questionnaire-12. This questionnaire was developed and validated by Goldberg and Williams [29] and adapted by Makowska and Merecz [30]. It was designed for use in nonpsychiatric medical consultations by neurologists to detect mental functioning changes in patients. GHQ was previously used to assess mental health in the MS population [19,31,32]. The questionnaire has 12 questions for assessing the general level of happiness, perceived stress, the experience of depressive and anxiety symptoms, and sleep disturbance over the last 4 weeks. The examinees should choose among four Likert-type responses on the scale, ranging from "less than usual" to "much more than usual." The total score ranges from 0 to 36 , with higher scores indicating a worse psychological condition. The Cronbach's alpha value for the study samples was 0.82 .

The Multidimensional Health Locus of Control Scale (MHLC) was first developed by Wallston, Strudler Wallston, and DeVellis [33], and then adapted and validated to Polish by Juczyński [34]. The MHLC has 18 items that assess participants' perception of how much control they have over their medical decisions, with scores assigned to two categories: internal HLC and external HLC. The external HLC comprises two subscales: power of others HLC (the belief that one's health is influenced by others, for example, physicians or other healthcare professionals) and chance HLC (the belief that one's health depends on chance, luck, or fate). Each of these subscales consists of items with a 6-point Likert-type response scale, ranging from 1 (strongly disagree) to 6 (strongly agree), with higher scores indicating a more intense HLC in a given dimension. MHLC has been used in previous studies with a group of people with MS [35-37]. The internal consistency rates in this study for internal, power of others, and chance HLC scales were $0.72,0.80$, and 0.68 , respectively.

The self-efficacy of PwMS was measured using the Generalized Self-Efficacy Scale (GSES) [38], which was designed to assess the strength of one's belief in his/her own abilities to respond to novel or difficult situations. The GSES was adapted to polish by Juczynski [34]. The scale consists of 10 items with a 4-point scale, ranging from 1 (not at all true) to 4 (exactly true), with higher scores indicating higher self-efficacy. GSES has been 
used in previous studies with a group of people with MS [39-41].The internal consistency rate of GSES in the study samples amounted to 0.96 .

The clinical and demographic data of participants were collected using a standardized questionnaire. The clinical variables assessed in the study were as follows: illness duration, MS subtype, and overall MS severity, evaluated using the Expanded Disability Status Scale (EDSS) [42]. The EDSS is extensively used to assess the progression of disease and neurological disability. The scale spans from EDSS 0 (normal neurological examination) to EDSS 10 (death from MS) in half-point increments starting from EDSS 1. The EDSS scores and MS subtype of participants were determined by a neurologist. Gender, age, educational level, place of residence, employment, monthly income of one family member, and marital status were the sociodemographic variables analyzed in the study.

\subsection{Data Analysis}

\subsubsection{Matching Samples and Preliminary Analysis}

By propensity score matching, the control group (2017) was formed by matching PwMS who were examined in November 2020 (during the second wave of the COVID19 epidemic) with the PwMS examined in 2017 using the 1:1 nearest neighbor method. The following variables were considered for matching: age, gender, level of education, and EDSS scores. After matching, a preliminary analysis was performed by comparing demographic, socioeconomic, illness, and psychological variables between the two groups using Mann-Whitney test (Z), Pearson's chi-square test, and maximum likelihood chisquare test.

Finally, a well-balanced cohort of 113 paired PwMS (assessed in 2020 and 2017) was analyzed (Table 1). In terms of matching variables, the control group (2017) did not differ from the study group (2020); however, the extracted group of 113 respondents differed from the total sample of $382 \mathrm{PwMS}$ included in 2017. The mean age of the extracted participants was 43.1 years $(S D=10.3)$ and that of the total sample was 46.4 years $(S D=11.9)$, which showed a significant difference $(Z=2.75, p=0.006)$. The mean EDSS score of the control group was $3.31(\mathrm{SD}=0.81)$ and that of the total sample was $4.35(\mathrm{SD}=1.68)$, and this difference was also significant $(Z=5.90, p<0.001)$. No significant differences were found between the extracted sample and the total sample studied in 2017 with regard to gender $(p=0.409)$ and level of education $(p=0.119)$.

Table 1. Socio-demographic and clinical characteristic of persons with MS studied in 2020 and control group studied in 2017.

\begin{tabular}{|c|c|c|c|c|c|}
\hline \multirow[b]{2}{*}{$\begin{array}{l}\text { Socio-Demographic, Clinical, and } \\
\text { Psychological Characteristics }\end{array}$} & \multicolumn{4}{|c|}{ Persons with MS } & \multirow[b]{2}{*}{$p$ Value } \\
\hline & \multicolumn{2}{|c|}{$\begin{array}{l}\text { Study Group } \\
\quad(n=113)\end{array}$} & \multicolumn{2}{|c|}{$\begin{array}{l}\text { Control Group } \\
\quad(n=113)\end{array}$} & \\
\hline & \multicolumn{4}{|c|}{ Matching variables } & \\
\hline Age (years \pm SD) & \multicolumn{2}{|c|}{$42.2 \pm 9.3$} & \multicolumn{2}{|c|}{$43.1 \pm 10.3$} & $0.603^{a}$ \\
\hline \multicolumn{6}{|l|}{ Gender $n(\%)$} \\
\hline Male & 41 & $(36.3)$ & 42 & $(37.2)$ & $0.890^{\mathrm{b}}$ \\
\hline Female & 72 & $(63.7)$ & 71 & $(62.8)$ & \\
\hline \multicolumn{6}{|l|}{ Education $n(\%)$} \\
\hline Primary & 2 & $(1.8)$ & 1 & $(0.9)$ & \\
\hline Vocational & 35 & $(31.0)$ & 39 & $(34.5)$ & $0.879^{\mathrm{c}}$ \\
\hline Secondary & 40 & $(35.4)$ & 37 & $(32.7)$ & \\
\hline Higher & 36 & (31.9) & 36 & $(31.9)$ & \\
\hline Disability EDSS (mean \pm SD) & \multicolumn{2}{|c|}{$3.31 \pm 0.9$} & \multicolumn{2}{|c|}{$3.31 \pm 0.8$} & $0.916^{\mathrm{a}}$ \\
\hline
\end{tabular}


Table 1. Cont.

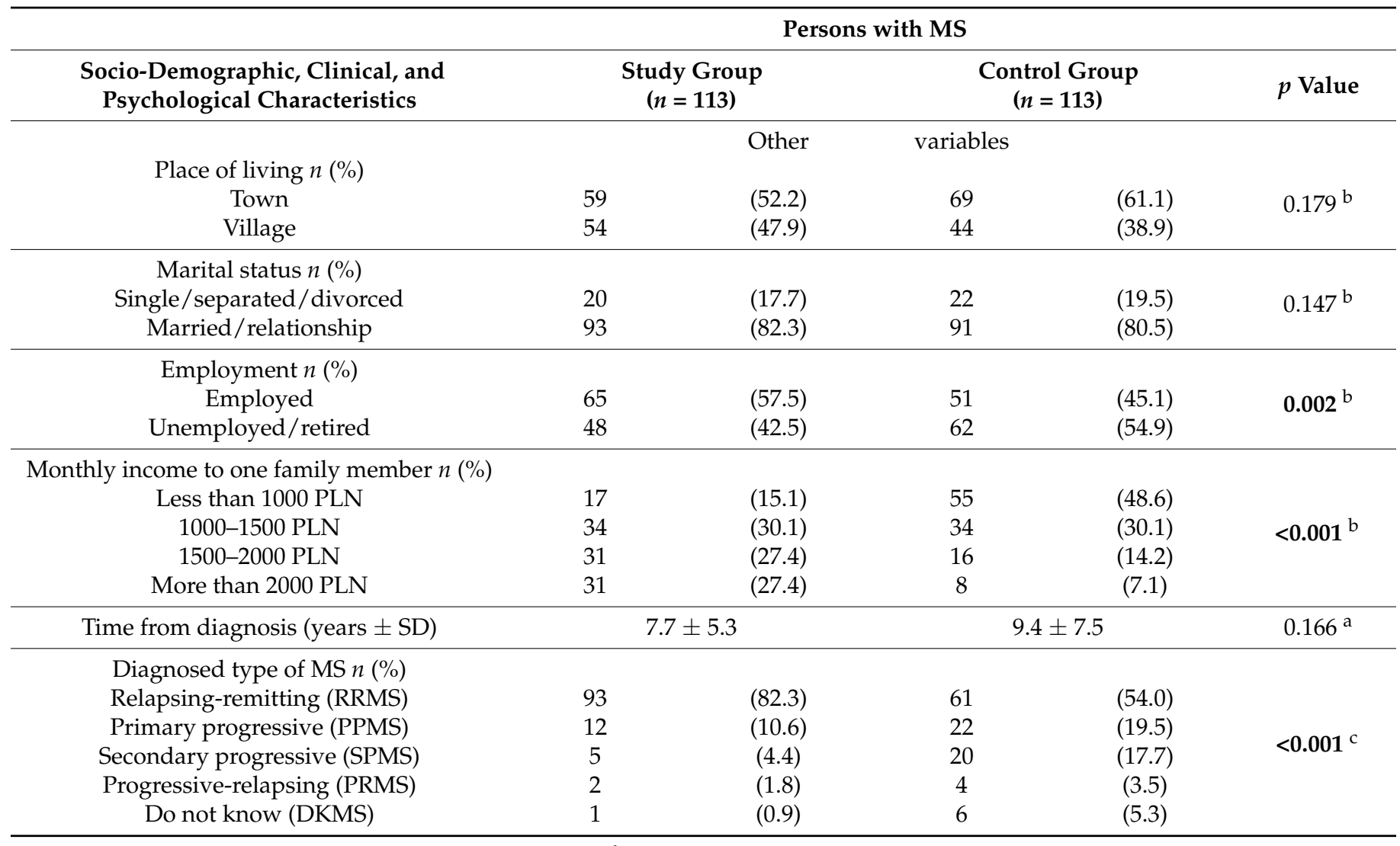

Note: ${ }^{a}$ Mann-Whitney test; ${ }^{b}$ Pearson's chi-square test; ${ }^{c}$ maximum likelihood chi-square test; bold values indicate statistically significant differences.

\subsubsection{Main Analysis}

First, the data collected for the study were screened and checked against the assumptions of the regression analysis. Then, the presence and power of relationships between all independent variables (demographic, socioeconomic, illness, and psychological) and the dependent variable (mental health outcomes) was determined using the Mann-Whitney test $(Z)$, Kruskal-Wallis test $(H)$, and Spearman correlation $\left(r_{\mathrm{s}}\right)$, in order to verify whether these variables should be controlled in future analyses. Finally, two separate hierarchical multiple regression analyses were performed, with mental health scores as dependent variables for the 2020 group (study group) and 2017 group (control group). Only the factors that were significantly associated with mental health outcome were included in the models. The level of statistical significance for the inclusion of independent variables in multiple regression models was set at $p<0.05$. All statistical analyses were carried out in Statistica software, version 4.0.67 (StatSoft Polska, www.statsoft.pl).

\section{Results}

\subsection{Study Participants}

The mean age of both $2020(n=113)$ and $2017(n=113)$ groups was just above 40 years. About two-thirds of the participants in the groups were female, and more than $60 \%$ of the participants had secondary or higher education (Table 1). The disability status was almost the same in the study and control group (EDSS $=3.31$ ). The majority of participants in the groups lived in towns, and were married. Significant differences were found in employment status between the groups $(p=0.011)$. The post hoc analysis revealed that $57.5 \%$ of PwMS were employed in 2020 and 45.1\% were employed in $2017(p=0.004)$. Similarly, significant differences were noted between the groups in terms of the monthly income of one family member $(p<0.001)$. The post hoc analysis indicated that more PwMS 
in the 2020 group had a monthly income of above 2000 PLN $(p<0.001)$, and an income between 1500 PLN and 2000 PLN $(p=0.013)$ in comparison to the control group studied in 2017. By contrast, a lower number of PwMS had a monthly income below 1000 PLN in 2020 than in $2017(p<0.001)$. The mean time elapsed from the MS diagnosis was 7.4 years in the 2020 group and 9.4 years in the 2017 group, but this difference was not significant. Significant differences were noted in the subtype of MS $(p<0.001)$. The post hoc analysis showed that more PwMS in 2020 had relapsing-remitting MS (82.3\%) than in 2017 (54.0\%), and this difference was significant $(p<0.001)$. On the other hand, less PwMS had secondary progressive MS in $2020(4.4 \%)$ than in $2017(17.7 \%)$, and this difference was also significant $(p=0.001)$.

\subsection{Comparison of Mental Health and Psychological Factors in a Study and Control Group}

No significant differences were identified between the groups with regard to mental health and general self-efficacy (Table 2). Significant differences were found with regard to the three forms of HLC (internal $(p<0.001)$, powerful others $(p=0.008)$, and chance $(p<0.001))$, which are the three psychological variables of the study, between the analyzed groups. In all cases, higher mean scores were observed in the control group (2017) in comparison to the study group (2020). The Cohen's d effect size was used to evaluate the clinical value of the differences in the outcomes of both groups. The Cohen's d effect for internal HLC was 0.603, for chance HLC 0.657 and for powerful others HLC 0.334.

Table 2. Comparison of mental health and psychological factors of persons with MS studied in 2020 and control group studied in 2017.

\begin{tabular}{|c|c|c|c|}
\hline \multirow[b]{2}{*}{ Psychological Factors (Mean \pm SD) } & \multicolumn{2}{|c|}{ Persons with MS } & \multirow[b]{2}{*}{$p$ Value } \\
\hline & $\begin{array}{l}\text { Study Group } \\
\quad(n=113)\end{array}$ & $\begin{array}{l}\text { Control Group } \\
\quad(n=113)\end{array}$ & \\
\hline Mental health & $29.24 \pm 4.00$ & $28.72 \pm 5.45$ & $0.710^{\mathrm{a}}$ \\
\hline General self-efficacy & $31.05 \pm 5.30$ & $29.83 \pm 5.20$ & $0.079^{\mathrm{a}}$ \\
\hline Health locus of control-internal & $21.89 \pm 4.30$ & $24.50 \pm 4.35$ & $<0.001^{a}$ \\
\hline Health locus of control-others & $24.18 \pm 4.46$ & $25.72 \pm 4.76$ & $0.008^{a}$ \\
\hline Health locus of control-chance & $21.88 \pm 4.17$ & $24.92 \pm 4.63$ & $<0.001^{a}$ \\
\hline
\end{tabular}

Note: ${ }^{a}$ Mann-Whitney test; bold values indicate statistically significant differences.

\subsection{Associations of Independent Variables with Mental Health in Study and Control Groups}

The coefficients of association between all independent variables and mental health scores in PwMS (study and control groups) are presented in Table 3. For the study group (2020), seven factors were found to be significantly associated with mental health scores i.e., gender $(p=0.024)$, level of education $(p=0.022)$, employment status $(p=0.043)$, time from diagnosis $(p=0.007)$, diagnosed MS subtype $(p=0.018)$, general self-efficacy $(p<0.001)$, HLC-internal $(p=0.009)$. In the case of the control group (2017), significant association with mental health scores were found for nine factors i.e., age $(p<0.001)$, gender $(p=0.049)$, marital status $(p=0.046)$, level of education $(p<0.001)$, employment status $(p=0.002)$, monthly income of one family member $(p<0.001)$, general self-efficacy $(p<0.001)$, HLC—internal $(p<0.001)$, and HLC—chance $(p=0.003)$. 
Table 3. Associations between selected independent variables and mental health in persons with MS studied in 2020 and control group studied in 2017.

\begin{tabular}{|c|c|c|c|c|}
\hline \multirow[b]{3}{*}{ Independent Variables } & \multicolumn{4}{|c|}{ Mental Health } \\
\hline & \multicolumn{2}{|c|}{$\begin{array}{l}\text { Study Group } \\
\quad(n=113)\end{array}$} & \multicolumn{2}{|c|}{$\begin{array}{l}\text { Control Group } \\
\quad(n=113)\end{array}$} \\
\hline & Statistical Test & $p$ Value & Statistical Test & $p$ Value \\
\hline \multicolumn{5}{|l|}{ Demographic factors } \\
\hline Age & $r_{S}=0.05$ & 0.570 & $r_{S}=0.32$ & $<0.001$ \\
\hline Gender & $\mathrm{Z}=2.25$ & 0.024 & $\mathrm{Z}=1.97$ & 0.049 \\
\hline Marital status & $Z=-0.53$ & 0.593 & $Z=-1.99$ & 0.046 \\
\hline Education & $\mathrm{H}=9.67$ & 0.022 & $\mathrm{H}=16.69$ & $<0.001$ \\
\hline Place of living & $Z=1.72$ & 0.086 & $\mathrm{Z}=1.41$ & 0.159 \\
\hline \multicolumn{5}{|l|}{ Socioeconomic factors } \\
\hline Employment & $Z=-2.02$ & 0.043 & $Z=-3.12$ & 0.002 \\
\hline Monthly income & $\mathrm{H}=3.24$ & 0.356 & $\mathrm{H}=18.65$ & $<0.001$ \\
\hline \multicolumn{5}{|l|}{ Illness factors } \\
\hline Disability EDSS & $r_{S}=0.10$ & 0.302 & $r_{S}=0.01$ & 0.910 \\
\hline Time from diagnosis & $\mathrm{r}_{\mathrm{S}}=0.25$ & 0.007 & $r_{S}=0.12$ & 0.205 \\
\hline Diagnosed type of MS & $\mathrm{H}=11.91$ & 0.018 & $\mathrm{H}=5.56$ & 0.234 \\
\hline \multicolumn{5}{|l|}{ Psychological factors } \\
\hline General self-efficacy & $r_{s}=-0.32$ & $<0.001$ & $r_{S}=-0.48$ & $<0.001$ \\
\hline Health locus of control-internal & $\mathrm{r}_{\mathrm{s}}=-0.24$ & 0.009 & $\mathrm{r}_{\mathrm{S}}=-0.39$ & $<0.001$ \\
\hline Health locus of control—others & $\mathrm{r}_{\mathrm{S}}=-0.15$ & 0.123 & $r_{S}=0.03$ & 0.719 \\
\hline Health locus of control-chance & $\mathrm{r}_{\mathrm{S}}=0.04$ & 0.711 & $r_{S}=0.27$ & 0.003 \\
\hline
\end{tabular}

Note: Spearman correlation $\left(\mathrm{r}_{\mathrm{s}}\right)$; Mann-Whitney test (Z); Kruskal-Wallis test (H); bold values indicate statistically significant associations.

\subsection{Hierarchical Multiple Regression}

Two separate hierarchical multiple regression analyses were carried out using mental health scores as a dependent variable (Table 4).

Table 4. Regression analysis predicting mental health in persons with MS studied in 2020 and control group studied in 2017.

\begin{tabular}{ccccc}
\hline Variable & $\boldsymbol{R}^{\mathbf{2}}$ & $\boldsymbol{\beta}$ & $\boldsymbol{F}$ & $p$ Value \\
\hline Model 1 Study group 2020 & 0.18 & & 7.94 & $<\mathbf{0 . 0 0 1}$ \\
General self-efficacy & & -0.21 & & $\mathbf{0 . 0 3 2}$ \\
Health locus of control-internal & & -0.21 & & $\mathbf{0 . 0 3 5}$ \\
Education & 0.48 & -0.18 & & $\mathbf{0 . 0 4 8}$ \\
Model 2 Control group 2017 & & -0.31 & 33.32 & $<\mathbf{0 . 0 0 1}$ \\
General self-efficacy & & 0.45 & & $<\mathbf{0 . 0 0 1}$ \\
Health locus of control-chance & -0.37 & & $<\mathbf{0 . 0 0 1}$ \\
Health locus of control-internal & & & $<\mathbf{0 . 0 1}$ \\
\hline
\end{tabular}

Bold values indicate statistically significant associations.

In the first regression model of the 2020 study group, three out of seven factors related to mental health, namely general self-efficacy $(\beta=-0.21, p=0.032)$, HLC - internal $(\beta=-0.21, p=0.035)$, and education $(\beta=-0.18, p=0.048)$, which were significantly associated with the dependent variable, were included. In the regression analysis, all these three factors were identified as significant correlates of mental health in MS. Persons with vocational education were found to have significantly lower mental health compared to those with secondary $(p=0.013)$ and higher education $(p=0.002)$. Although the model reached the threshold of statistical significance, it explained only $18 \%$ of the variance in mental health in MS $\left(R^{2}=0.18, F(3.109)=7.94, p<0.001\right)$. 
In the second regression model of the 2017 control group, three out of nine factors related to mental health, namely self-efficacy $(\beta=-0.31, p<0.001)$, HLC - chance $(\beta=0.45$, $p<0.001)$, and HLC - internal $(\beta=-0.37, p<0.001)$, which were significantly associated with the dependent variable, were included. All of them were identified as significant correlates of mental health in MS. The model was significant and explained $48 \%$ of the variance in mental health in $\mathrm{MS}\left(R^{2}=0.48, F(3.109)=33.32, p<0.001\right)$.

\section{Discussion}

A comparison of mental health parameters of two similar PwMS groups in Polandone studied before the pandemic and the other during the second wave of the pandemicshowed no differences between the groups in mental health status. Thus, the results support the thesis, and, also, those research results indicating that there is no relationship between the pandemic and deterioration of mental health in PwMS. This situation may be similar to that of the general population. Although numerous reports have shown that the mental health of the general population has been drastically affected, along with a higher prevalence of depression, anxiety, and stress during a lockdown and increased cases of suicides, the first major meta-analysis of longitudinal studies and natural experiments showed that lockdowns do not have uniformly detrimental effects on mental health and that most people are psychologically resilient to their effects [43]. Moreover, evidence suggests that MS experience immunizes an individual, to some extent, against the negative emotional consequences of a pandemic. For example, Chiaravalloti and colleagues [2] reported that PwMS wanted to safeguard themselves early in the pandemic due to their heightened risk of infection and subjective emotions of vulnerability. As they were careful in following safety precautions, their attempts of self-protection may have boosted their comfort level, reducing anxiety and depression. In addition, because of their illness and associated disability, PwMS more often experience social isolation, and may, therefore, find it easier to adapt to lockdown restrictions $[44,45]$. Another explanation is living in fear of one's own health due to COVID-19. PwMS have dealt with this feeling since their diagnosis of MS, which is an unpredictable, uncertain, and uncontrollable disease, and thus can easier deal with the discomfort that comes with it $[16,46,47]$. Finally, based on their previous experience coping with a chronic condition and attacks, PwMS may have evolved more effective ways to manage stress during the acute COVID-19 outbreak [16]. All these assumptions certainly require more in-depth research in order to arrive at final conclusions.

Regarding the second goal of this study, the analyzed groups did not differ in terms of general self-efficacy. Thus, our results do not support those researchers who indicate that COVID-19 and lockdown significantly decreased the sense of self-efficacy in the general population $[48,49]$. Perhaps, in PwMS, self-efficacy beliefs are more stable, developed in coping with MS and more resistant to changing external conditions. Certainly, in order to provide an unambiguous answer, it is worth undertaking more in-depth research in this direction. Additionally, both regression analysis of the present study revealed the importance of self-efficacy in mental health which confirms the results of other studies $[50,51]$, including those undertaken during the pandemic [45].

Significant differences were noted in HLC between the studied groups. For all three forms of HLC (internal, powerful others, and chance), higher mean scores were observed for the group studied in 2017 in comparison to the 2020 group. This is partly confirmed by reports from the general population indicating subjective loss of control during the pandemic, as a reaction to extensive restrictions and the unpredictability of the pandemic's dynamics [27]. However, these studies while pointing to a decrease in the internal HLC, at the same time indicated an increase in the external HLC, which we did not observe in our studies. Perhaps, a pandemic generally lowers the sense of control over one's health (internal or external) in PwMS, but this conclusion should be confirmed by more targeted, population-extended studies. Undoubtedly, the unidirectional changes in HLC dimensions constitute another argument for the thesis that HLC dimensions are independent of each other and require a separate investigation [52]. 
Regarding the relationship of HLC with mental health, an association between internal HLC and better mental health was found in both studied groups. This result is further evidence of the positive importance of the internal HLC in shaping the well-being of PwMS [19,36], and the pandemic did not contribute to changes in this regard.

Other variables included in the regression analysis indicated that education was significant correlate of mental health during the pandemic. More precisely, persons with vocational education were characterized by significantly lower mental health compared to those with secondary and higher education. It can be speculated that a higher level of knowledge and awareness of the course of COVID-19 can support mental functioning in PwMS, which suggests the need for further research in this area.

This study has several limitations. First, due to its cross-sectional nature, the study did not allow drawing any conclusions regarding the direction of causal relationships between the analyzed variables. The second limitation is the difficulty in generalizing the results of the study to the PwMS population in other countries. The course of the COVID-19 pandemic and lockdown restrictions differed in individual countries, which certainly may have had an impact on the mental well-being of PwMS. Moreover, it was unclear whether the respondents had previously suffered from COVID-19. It should be mentioned that the history of this disease and its severity may significantly influence the mental health of individuals. Third, people suffering from cognitive disorders, which are a frequent consequence of MS, were excluded from the study. Cognitive impairments were only assessed based on a subjective neurological examination, but were not confirmed by any objective tool, and so this exclusion criterion is unreliable. Finally, the study did not identify any difficulties or barriers directly experienced by respondents as a result of the pandemic. Their detailed identification and analysis of their relationships with mental health should be the goal of further research on the mental functioning of PwMS in a pandemic.

Despite these limitations, the findings of this study demonstrate that the pandemic and the related lockdown were not associated with mental health status of PwMS in Poland. The results contradict the popular belief that the pandemic has had a negative effect on the mental health of people. At the same time, it was noted that well known determinants of mental health, such as self-efficacy and HLC seemed to retain their prominent role for mental functioning in the pandemic. However, while self-efficacy did not change, all categories of HLC decreased, compared to the pre-pandemic period. Further research should focus on clarifying the role of HLC, in order to help mental health specialists appropriately guide their patients during the pandemic.

Author Contributions: M.W.: Conceptualization, Methodology, Formal analysis, Writing-original draft, Writing-review and editing, Project administration. M.K.: Conceptualization, Methodology, Investigation, Data curation, Visualization, Writing-original draft and editing. J.G.: Conceptualization, Methodology, Data curation, Writing-review and editing. W.B.: Resources, Investigation, Data curation. T.T.: Conceptualization, Methodology, Formal analysis, Resources, Writing-review and editing, Supervision. All authors have read and agreed to the published version of the manuscript.

Funding: This study was funded by the Polish Ministry of Science and Higher Education for the statutory research activities of the Poznan University of Physical Education (BS/2017/20). Project financed under the program the Minister of Education and Science called "Regional Initiative of Excellence" in the years 2019-2022, project no. 024/RID/2018/19, amount of financing 11999 000,00 PLN.

Institutional Review Board Statement: The study was conducted in accordance with the Declaration of Helsinki, and approved by the Bioethical Commission of Poznan University of Medical Sciences. (protocol code KB/276/20 11 March 2020).

Informed Consent Statement: Informed consent was obtained from all subjects involved in the study.

Data Availability Statement: The data that support the findings of this study are openly available in RepOD at https:/ / doi.org/10.18150/GLZKEP (accessed on 15 January 2022). 
Acknowledgments: The authors would like to gratefully acknowledge all the individuals with multiple sclerosis who completed the questionnaire, and Magdalena Lewandowska for her assistance in statistical analysis.

Conflicts of Interest: The authors declare no conflict of interest.

Ethical Approval: This study was performed in line with the principles of the Declaration of Helsinki. Approval was granted by Bioethical Commission of Poznan University of Medical Sciences. Informed consent was obtained from all individual participants and study partners included in the study.

\section{References}

1. Barański, K.; Brożek, G.; Kowalska, M.; Kaleta-Pilarska, A.; Zejda, J.E. Impact of COVID-19 Pandemic on Total Mortality in Poland. Int. J. Environ. Res. Public Health 2021, 18, 4388. [CrossRef] [PubMed]

2. Chiaravalloti, N.D.; Amato, M.P.; Brichetto, G.; Chataway, J.; Dalgas, U.; DeLuca, J.; Meza, C.; Moore, N.B.; Feys, P.; Filippi, M.; et al. The emotional impact of the COVID-19 pandemic on individuals with progressive multiple sclerosis. J. Neurol. 2021, 268, 1598-1607. [CrossRef] [PubMed]

3. Zanghì, A.; D'Amico, E.; Luca, M.; Ciaorella, M.; Basile, L.; Patti, F. Mental health status of relapsing-remitting multiple sclerosis Italian patients returning to work soon after the easing of lockdown during COVID-19 pandemic: A monocentric experience. Mult. Scler. Relat. Disord. 2020, 46, 102561. [CrossRef] [PubMed]

4. Dubey, S.; Biswas, P.; Ghosh, R.; Chatterjee, S.; Dubey, M.J.; Chatterjee, S.; Lahiri, D.; Lavie, C.J. Psychosocial impact of COVID-19. Diabetes Metab. Syndr. 2020, 14, 779-788. [CrossRef]

5. Gallagher, M.W.; Zvolensky, M.J.; Long, L.J.; Rogers, A.H.; Garey, L. The Impact of COVID-19 Experiences and Associated Stress on Anxiety, Depression, and Functional Impairment in American Adults. Cogn. Ther. Res. 2020, 44, 1043-1051. [CrossRef]

6. Petzold, M.B.; Bendau, A.; Plag, J.; Pyrkosch, L.; Maricic, L.M.; Betzler, F.; Rogoll, J.; Große, J.; Ströhle, A. Risk, resilience, psychological distress, and anxiety at the beginning of the COVID-19 pandemic in Germany. Brain Behav. 2020, 10 , e01745. [CrossRef]

7. Rahman, M.A.; Hoque, N.; Alif, S.M.; Salehin, M.; Islam, S.M.S.; Banik, B.; Sharif, A.; Nazim, N.B.; Sultana, F.; Cross, W. Factors associated with psychological distress, fear and coping strategies during the COVID-19 pandemic in Australia. Glob. Health 2020, 16, 95. [CrossRef]

8. Boeschoten, R.E.; Braamse, A.M.J.; Beekman, A.T.F.; Cuijpers, P.; van Oppen, P.; Dekker, J.; Uitdehaag, B.M.J. Prevalence of depression and anxiety in Multiple Sclerosis: A systematic review and meta-analysis. J. Neurol. Sci. 2017, 372, 331-341. [CrossRef]

9. Costabile, T.; Carotenuto, A.; Lavorgna, L.; Borriello, G.; Moiola, L.; Inglese, M.; Petruzzo, M.; Trojsi, F.; Ianniello, A.; Nozzolillo, A.; et al. COVID-19 pandemic and mental distress in multiple sclerosis: Implications for clinical management. Eur. J. Neurol. 2021, 28, 3375-3383. [CrossRef]

10. Bonavita, S.; Sparaco, M.; Russo, A.; Borriello, G.; Lavorgna, L. Perceived stress and social support in a large population of people with multiple sclerosis recruited online through the COVID-19 pandemic. Eur. J. Neurol. 2021, 28, 3396-3402. [CrossRef]

11. Motolese, F.; Rossi, M.; Albergo, G.; Stelitano, D.; Villanova, M.; Di Lazzaro, V.; Capone, F. The Psychological Impact of COVID-19 Pandemic on People with Multiple Sclerosis. Front. Neurol. 2020, 11, 580507. [CrossRef] [PubMed]

12. Morris-Bankole, H.; Ho, A.K. The COVID-19 Pandemic Experience in Multiple Sclerosis: The Good, the Bad and the Neutral. Neurol. Ther. 2021, 10, 279-291. [CrossRef] [PubMed]

13. Chiu, C.; Wilcher, K.; Jones, A. Perceived COVID-19 Impacts on Stress, Resilience, and Mental Health among People with Multiple Sclerosis: A Longitudinal Prospective Study. J. Rehabil. 2021, 87, 80-87.

14. Alschuler, K.N.; Roberts, M.K.; Herring, T.E.; Ehde, D.M. Distress and risk perception in people living with multiple sclerosis during the early phase of the COVID-19 pandemic. Mult. Scler. Relat. Disord. 2021, 47, 102618. [CrossRef] [PubMed]

15. Capuano, R.; Altieri, M.; Bisecco, A.; D’Ambrosio, A.; Docimo, R.; Buonanno, D.; Matrone, F.; Giuliano, F.; Tedeschi, G.; Santangelo, G.; et al. Psychological consequences of COVID-19 pandemic in Italian MS patients: Signs of resilience? J. Neurol. 2021, 268, 743-750. [CrossRef]

16. Altunan, B.; Unal, A.; Bingöl, A.; Dilek, F.; Girgin, D. Coping with stress during the first wave of the COVID-19 pandemic by Turkish people with Multiple Sclerosis: The relationship between perceived stress and quality of life. Mult. Scler. Relat. Disord. 2021, 53, 103039. [CrossRef]

17. Stojanov, A.; Malobabic, M.; Milosevic, V.; Stojanov, J.; Vojinovic, S.; Stanojevic, G.; Stevic, M. Psychological status of patients with relapsing-remitting multiple sclerosis during coronavirus disease-2019 outbreak. Mult. Scler. Relat. Disord. 2020, $45,102407$. [CrossRef]

18. Wilski, M.; Tomczak, M. Comparison of Personal Resources in Patients Who Differently Estimate the Impact of Multiple Sclerosis. Ann. Behav. Med. 2017, 51, 179-188. [CrossRef]

19. Wilski, M.; Brola, W.; Tomczak, M. Health locus of control and mental health in patients with multiple sclerosis: Mediating effect of coping strategies. Res. Nurs. Health 2019, 42, 296-305. [CrossRef]

20. Wilski, M.; Kocur, P.; Brola, W.; Tasiemski, T. Psychological factors associated with self-management in multiple sclerosis. Acta Neurol. Scand. 2020, 142, 50-57. [CrossRef] 
21. Del Puente, G.; Mahamid, A.; Bragazzi, N. Health Locus of Control and Multiple Sclerosis: A Systematic Review. J. Psychol. Psychother. 2012, S3, 1-4. [CrossRef]

22. Bandura, A. Self-Efficacy: The Exercise of Control; W. H. Freeman: New York, NY, USA; Henry Holt \& Co.: New York, NY, USA, 1997; Volume ix, p. 604.

23. Bidzan, M.; Bidzan-Bluma, I.; Szulman-Wardal, A.; Stueck, M.; Bidzan, M. Does self-efficacy and emotional control protect hospital staff from COVID-19 Anxiety and PTSD symptoms? Psychological functioning of hospital staff after the announcement of COVID-19 Coronavirus Pandemic. Front. Psychol. 2020, 11, 552583. [CrossRef] [PubMed]

24. Zhou, C.; Yue, X.D.; Zhang, X.; Shangguan, F.; Zhang, X.Y. Self-efficacy and mental health problems during COVID-19 pandemic: A multiple mediation model based on the Health Belief Model. Pers. Individ. Differ. 2021, 179, 110893. [CrossRef]

25. Krampe, H.; Danbolt, L.J.; Haver, A.; Stålsett, G.; Schnell, T. Locus of control moderates the association of COVID-19 stress and general mental distress: Results of a Norwegian and a German-speaking cross-sectional survey. BMC Psychiatry 2021, $21,437$. [CrossRef] [PubMed]

26. Sigurvinsdottir, R.; Thorisdottir, I.E.; Gylfason, H.F. The Impact of COVID-19 on Mental Health: The Role of Locus on Control and Internet Use. Int. J. Environ. Res. Public Health 2020, 17, 6985. [CrossRef] [PubMed]

27. Misamer, M.; Signerski-Krieger, J.; Bartels, C.; Belz, M. Internal locus of control and sense of coherence decrease during the COVID-19 pandemic: A survey of students and professionals in social work. Front. Sociol. 2021, 6, 174. [CrossRef]

28. Polman, C.H.; Reingold, S.C.; Banwell, B.; Clanet, M.; Cohen, J.A.; Filippi, M.; Fujihara, K.; Havrdova, E.; Hutchinson, M.; Kappos, L.; et al. Diagnostic criteria for multiple sclerosis: 2010 revisions to the McDonald criteria. Ann. Neurol. 2011, 69, $292-302$. [CrossRef]

29. Goldberg, D.P.; Williams, P. A User's Guide to the General Health Questionnaire; NFER-NELSON: London, UK, 1991.

30. Williams, P.; Merecz, D.; Goldberg, D.P.; Makowska, Z.; Nofer Institute of Occupational Medicine. Ocena Zdrowia Psychicznego na Podstawie Badań Kwestionariuszami Davida Goldberga: Podręcznik Dla Użytkowników Kwestionariuszy GHQ-12 i GHQ-28; Oficyna Wydawnicza IMP: Łódź, Poland, 2001. (In Polish)

31. Rabins, P.V.; Brooks, B.R. Emotional disturbance in multiple sclerosis patients: Validity of the General Health Questionnaire (GHQ). Psychol. Med. 1981, 11, 425-427. [CrossRef]

32. Aymerich, M.; Guillamón, I.; Jovell, A.J. Health-related quality of life assessment in people with multiple sclerosis and their family caregivers. A multicenter study in Catalonia (Southern Europe). Patient Prefer. Adherence 2009, 3, 311-321. [CrossRef]

33. Wallston, K.A.; Wallston, B.S.; DeVellis, R. Development of the Multidimensional Health Locus of Control (MHLC) Scales. Health Educ. Monogr. 1978, 6, 160-170. [CrossRef]

34. Juczyński, Z. Measurement Tools in Promotion and Health Psychology; Laboratory of Psychological Testing of the Polish Psychological Association: Warsaw, Poland, 2001.

35. Schwartz, C.E. Teaching coping skills enhances quality of life more than peer support: Results of a randomized trial with multiple sclerosis patients. Health Psychol. 1999, 18, 211-220. [CrossRef] [PubMed]

36. Bragazzi, N.L. The Gap in the Current Research on the Link between Health Locus of Control and Multiple Sclerosis: Lessons and Insights from a Systematic Review. Mult. Scler. Int. 2013, 2013, 972471. [CrossRef] [PubMed]

37. Wilski, M.; Tomczak, M.; Ferlak, J.; Chmielewski, B.; Łuniewska, M.; Brola, W. Coping profiles in multiple sclerosis: Comparison of personal resources. Mult. Scler. Relat. Disord. 2021, 53, 103027. [CrossRef] [PubMed]

38. Schwarzer, R.; Jerusalem, M. Generalized self-efficacy scale. In Measures in Health Psychology: A User's Portfolio. Causal and Control Beliefs; Weinman, J., Wright, S., Johnston, M., Eds.; NFER-NELSON: Windsor, UK, 1995; pp. 35-37.

39. Wilski, M.; Tasiemski, T.; Dabbrowski, A. Body Esteem Among Women with Multiple Sclerosis and its Relationship with Demographic, Clinical and Socio-Psychological Factors. Int. J. Behav. Med. 2016, 23, 340-347. [CrossRef] [PubMed]

40. Wilski, M.; Kocur, P.; Górny, M.; Koper, M.; Nadolska, A.; Chmielewski, B.; Tomczak, M. Perception of Multiple Sclerosis Impact and Treatment Efficacy Beliefs: Mediating Effect of Patient's Illness and Self-Appraisals. J. Pain Symptom Manag. 2019, 58, 437-444. [CrossRef] [PubMed]

41. Asgharkhah, E.; Shareh, H. Effectiveness of group metacognitive therapy in self-efficacy and defense styles in women with multiple sclerosis. J. Fundam. Ment. Health 2017, 19, 330-340. [CrossRef]

42. Kurtzke, J.F. Rating neurologic impairment in multiple sclerosis: An expanded disability status scale (EDSS). Neurology 1983, 33, 1444-1452. [CrossRef]

43. Prati, G.; Mancini, A.D. The psychological impact of COVID-19 pandemic lockdowns: A review and meta-analysis of longitudinal studies and natural experiments. Psychol. Med. 2021, 51, 201-211. [CrossRef]

44. Freeman, J.; Gorst, T.; Gunn, H.; Robens, S. "A non-person to the rest of the world": Experiences of social isolation amongst severely impaired people with multiple sclerosis. Disabil. Rehabil. 2020, 42, 2295-2303. [CrossRef]

45. Strober, L.; Weber, E.; Lequerica, A.; Chiaravalloti, N. Surviving a global pandemic: The experience of depression, anxiety, and loneliness among individuals with multiple sclerosis. Mult. Scler. Relat. Disord. 2022, 58, 103497.

46. Barker-Collo, S.; Cartwright, C.; Read, J. Into the unknown: The experiences of individuals living with multiple sclerosis. J. Neurosci. Nurs. 2006, 38, 435-441, 446. [CrossRef]

47. Malcomson, K.S.; Lowe-Strong, A.S.; Dunwoody, L. What can we learn from the personal insights of individuals living and coping with multiple sclerosis? Disabil. Rehabil. 2008, 30, 662-674. [CrossRef] [PubMed] 
48. Ritchie, L.; Cervone, D.; Sharpe, B.T. Goals and Self-Efficacy Beliefs During the Initial COVID-19 Lockdown: A Mixed Methods Analysis. Front. Psychol. 2021, 11, 559114. [CrossRef] [PubMed]

49. Yenen, E.T.; Çarkit, E. Fear of COVID-19 and general self-efficacy among Turkish teachers: Mediating role of perceived social support. Curr. Psychol. 2021, 1-9. [CrossRef] [PubMed]

50. Jongen, P.J.; Ruimschotel, R.; Heerings, M.; Hussaarts, A.; Duyverman, L.; Van Der Zande, A.; Valkenburg-Vissers, J.; Wolper, H.; Van Droffelaar, M.; Lemmens, W.; et al. Improved self-efficacy in persons with relapsing remitting multiple sclerosis after an intensive social cognitive wellness program with participation of support partners: A 6-months observational study. Health Qual. Life Outcomes 2014, 12, 40. [CrossRef]

51. Schmitt, M.M.; Goverover, Y.; Deluca, J.; Chiaravalloti, N. Self-efficacy as a predictor of self-reported physical, cognitive, and social functioning in multiple sclerosis. Rehabil. Psychol. 2014, 59, 27-34. [CrossRef]

52. Wallston, K.A. Hocus-pocus, the focus isn't strictly on locus: Rotter's social learning theory modified for health. Cogn. Res. 1992, 16, 183-199. [CrossRef] 